\title{
Sampling-standardized expansion and collapse of reef building in the Phanerozoic
}

\author{
Wolfgang Kiessling* \\ Museum für Naturkunde der Humboldt-Universität zu Berlin, Invalidenstraße 43, 10115 Berlin, Germany. \\ E-mail: wolfgang.kiessling@museum.hu-berlin.de
}

\begin{abstract}
Received 6 July 2007

Accepted 1 August 2007

Published 15 February 2008

\section{Key Words}

Reefs

Phanerozoic

fossil record

sampling bias

volatility

Tracing the variability of reef production over long temporal scales is important to approach natural processes favoring or suppressing reef growth. Raw compilations of reef abundance per unit of time do not necessarily depict biologically meaningful patterns, because the waxing and waning of reefs might just follow the quality of the fossil record, that is, the amount of paleontological information that is available in general. Here I standardize the published record of Phanerozoic reefs, as stored in the PaleoReefs database, to the published record of marine invertebrate fossils as stored in the Paleobiology Database. The sampling-standardized peaks in reef growth are essentially identical to those of previous studies, but significant peaks are rare. Times when unusual changes in ecological conditions are likely to control changes in metazoan reef proliferation were identified in the Late Devonian, Late Triassic, Late Jurassic and Neogene.
\end{abstract}

\section{Introduction and background}

Geologists have long suggested that the Phanerozoic record of marine reefs fluctuated considerably through time but exactly how strong these fluctuations were is still a matter of debate. The published graphs of several authors suggest moderate fluctuations in reef abundance over the Phanerozoic (James 1983; Copper 1988; James \& Bourque 1992; Hallock 1997), while other authors have depicted substantial variations, which increase with refinements of reef definitions (Wood 1993; Webb 1996; Kiessling et al. 1999, 2000; Kiessling 2002). Although there is more agreement on the timing of reef expansions and declines, the stratigraphic position and significance of reef booms are also poorly constrained. Resolving the issues of the temporal variability (= volatility) of reef growth and the position of reef booms and bursts is important for several reasons: First, identifying true peaks of reef growth can shed light on the global environmental conditions under which reefs tend to flourish. Second, the intensity of temporal fluctuations in reef abundance illuminates the sensitivity of reefs to extrinsic controls, be they environmental or biological. Third, insights can be gained into general processes of reef waxing and waning through time, because gradual increases and declines of reef abundance may suggest linear relation- ships between control and effect, whereas sharp peaks and drops could indicate non-linear relationships or even self-organization.

Two major problems hinder the detection of biologically meaningful patterns in reef production on geological time scales: Genuine variations in the preservation of sedimentary rocks and (economically driven) heterogeneities in exploration intensity (Kiessling 2005a, 2006). Kiessling (2006) has tried to compensate for much of this bias and uncovered the probable pattern of changes in absolute reef abundance and volume through the Phanerozoic. His pattern of a maximum proliferation of reefs in the Silurian and Devonian and a steep decline thereafter, interrupted by short-term peaks, provides insights into absolute changes in reef production, but does not elucidate variations relative to changes in the fossil record. These relative changes, however, can be even more informative than absolute changes. Imagine for example, that reef abundance were determined merely (and linearly) by available shelf area and thus controlled by sea-level fluctuations and hypsography. Then we could use the reef record to trace ancient sea levels but a prefect correlation between reef abundance and sea level would make it unlikely that any additional factors are relevant. Differences between preserved reef abundance and overall sampling of the fossil record can reveal times when ex- 
pansions and collapses were due to other factors such as changes in paleoclimate or biological innovations.

These differences are the focus of this study. I compare a comprehensive database on Phanerozoic reefs (the PaleoReefs database) with another comprehensive database of marine invertebrate fossils (the Paleobiology Database) to find biologically meaningful departures in reef production relative to the overall fossil record.

\section{Data and methods}

This study utilizes two large databases: The PaleoReefs database (PARED) and the Paleobiology Database (PBDB). The structure and data inventory of both databases have either been discussed elsewhere (Kiessling \& Flügel 2002) or are available online (http://paleodb.org). In brief, PARED compiles geological and paleontological information of Phanerozoic reef complexes and the PBDB hosts taxonomic collection data of Phanerozoic protists, plants and animals. A reef in PARED is defined as a "laterally confined biogenic structure, developed by the growth or activity of sessile benthic organisms and exhibiting topographic relief and (inferred) rigidity" (Flügel \& Kiessling 2002a). Although the information in both databases largely stems from the published literature, there are slightly different sampling strategies. In PARED virtually all data were collected by a single enterer (W. Kiessling) who tried to get all the available information on fossil reefs, irrespective of age and geographic setting, that is, no stratigraphic or geographic foci were a priori defined. The PBDB in contrast was compiled by a large suite of authorizers and enterers, with an often pronounced focus on particular time intervals. Although the time intervals that first suffered from less attention have later been filled with data to homogenize the time series, the sampling in PBDB probably represents a non-random fraction of the published literature. However, a random subset of the published literature (1\%) was extracted from GeoRef and analyzed in a project within the PBDB. Every hundredth accession number was obtained from GeoRef, which contained as keywords at least one of the major marine invertebrate phyla (Mollusca, Brachiopoda, Cnidaria, etc.). This 1\% subset (downloaded in summer 2003 by Michael Foote) contains 1175 references, 517 of which report original taxonomic collection data in peer-reviewed publications. Roughly $60 \%$ of these references have been entered until now, with all geological periods being proportionally equally represented by references, that is, $60 \%$ of the useful references available for each period have been entered. Therefore, collection counts in the $1 \%$ project should best reflect actual paleontological sampling intensity in the Phanerozoic. However, the fairly low number of references on which the collection counts are based (316) implies that individual references may contribute strongly to the estimate of sampling intensity. In other words, sampling peaks could be erroneously inferred when a few references report many collections from individual time intervals. This risk is much lower for the reef record and the total marine invertebrate record, which are based on 2573 and 4803 references, respectively. An additional sampling curve was thus created, which counts references instead of collections for the $1 \%$ data.

Other potential biases relate to the distribution of environmental settings and the distribution of geographic scales of collections in the PBDB. Data in PARED usually represent shallow marine carbonate environments and have a uniform geographic scale (Kiessling 2005b); whereas a variety of marine environments is present in the marine invertebrate data and an individual collection in the PBDB may represent a hand sample, small collection, an individual outcrop or even a local area or basin. This would be a bias only if some time intervals bear unusual departures from the overall distributions. A cursory look at the data suggests that there are no extreme outliers, except perhaps for an unusual concentration of "hand sample" data in the Cretaceous of the $1 \%$ project.

The stratigraphic resolution in both databases is variable, ranging from single ammonite zones to epochs. I apply here PBDB's standard subdivision of the Phanerozoic, which separates 49 intervals of roughly equally duration (Table 1). All reef records and collections that could not confidently be assigned to one of these intervals were excluded from the analyses. The total counts of usable data as of 29 June 2007 are: 2972 reef sites, 40417 marine invertebrate collections, and 2151 collections in the $1 \%$ project. These values represent between $84 \%$ and $89 \%$ of the total counts in each dataset.

The reef record was broken down further to provide biologically more meaningful patterns. I limited the partitioning to two further categories: The first subdivision considered only reefs dominated by metazoans and thus excluded microbial and algal reefs (metazoan reefs). The second subdivision was restricted to shallow-water reefs dominated by stony corals (tabulate, rugose or scleractinian corals) or hypercalcified sponges (archaeocyaths, stromatoporoids, chaetetids and pharetronids), which are not occurring in very high ( $>45$ degrees) paleolatitudes. The latter category is most similar to modern tropical coral reefs and therefore receives the most attention in the discussion. The discussion of ecological similarities between Paleozoic stromatoporoid-coral reefs and modern coral-algal reefs goes back and forth, usually focusing on the presence or absence of photosymbionts (Cowen 1988; Wood 1993). Although there may be profound ecological differences among the coral-sponge reefs, a more refined definition would not permit a complete Phanerozoic time series to be created.

The analysis consists of three steps: I first describe the time series in terms of general pattern, autocorrelations, trends, position of peaks, and volatility. Trends are explored with correlation tests of abundance versus age. Volatility is assessed by the standard deviation of first differences. Although standard measures of volatility use proportional rather than absolute changes (Kiessling 2006), this approach is not feasible here, because some reef time series include null values. However, the differences in scale need to be taken into account by calculating the standard deviation of first differences of normalized values (proportional differences from the mean). The volatility of an abundance value $N$ is thus computed by:

Volat $_{N}=\operatorname{std}\left(\left(N_{t} / \bar{N}_{t}\right)-\left(N_{t-1} / \bar{N}_{t}\right)\right)$.

In the second step, I apply statistical tests on the similarity of all curves to test the hypothesis that the reef record in PARED is actually related to the collection record in the PBDB. In the third step, I assess the standardized residuals (z-scores) of reef abundance regressed against the proxies of paleontological sampling. The standardization has the advantage of directly reporting values that can be used to assess the significance of outliers. I first use the raw counts because they are more intuitively understood, but the focus is on the pattern of first differences to circumvent the problem of autocorrelations. These sampling-standardized changes in reef abundance are then discussed in detail for coral-sponge reefs. All analyses were performed under R 2.5.1

\section{Sampling patterns}

The time series of reef abundance (Fig. 1) shows the same rugged pattern as in previous plots resolved to different time scales (Kiessling 2002, 2006). In spite of the volatile curves, there are significant lag one autocorrelations in the time series of metazoan reefs $\left(\mathrm{r}_{\mathrm{A}}=0.30, \mathrm{p}=0.03\right)$ and tropical coral-sponge reefs $\left(\mathrm{r}_{\mathrm{A}}=0.37, \mathrm{p}=0.008\right)$. Because these two curves are subsets of the "all reefs" curve, it comes as no surprise that they are strongly cross-correlated with the "all 
Table 1. Definition of time intervals used for all analyses.

\begin{tabular}{|c|c|c|c|}
\hline Interval number & Midpoint age (Ma) & Interval name & Included stages or epochs \\
\hline 1 & 536 & Cambrian 1 & Nemakit-Daldynian \\
\hline 2 & 521.5 & Cambrian 2 & Tommotian-Toyonian \\
\hline 3 & 507 & Cambrian 3 & Middle Cambrian \\
\hline 4 & 495.5 & Cambrian 4 & Late Cambrian \\
\hline 5 & 484.5 & Ordovician 1 & Tremadoc \\
\hline 6 & 472.5 & Ordovician 2 & "Arenig" \\
\hline 7 & 463.3 & Ordovician 3 & Llanvirn-Llandeilo \\
\hline 8 & 455 & Ordovician 4 & Caradoc \\
\hline 9 & 446.6 & Ordovician 5 & Ashgill \\
\hline 10 & 436 & Silurian 1 & Llandovery \\
\hline 11 & 423.2 & Silurian 2 & Wenlock-Pridoli \\
\hline 12 & 413.6 & Devonian 1 & Lochkovian-Pragian \\
\hline 13 & 400.5 & Devonian 2 & Emsian \\
\hline 14 & 387.8 & Devonian 3 & Eifelian-Givetian \\
\hline 15 & 379.9 & Devonian 4 & Frasnian \\
\hline 16 & 368.4 & Devonian 5 & Famennian \\
\hline 17 & 355.1 & Carboniferous 1 & Tournaisian \\
\hline 18 & 342.8 & Carboniferous 2 & Chadian-Asbian \\
\hline 19 & 327.1 & Carboniferous 3 & Brigantian-Serpukhovian \\
\hline 20 & 312.3 & Carboniferous 4 & Bashkirian-Moscovian \\
\hline 21 & 302.8 & Carboniferous 5 & Kasimovian-Gzhelian \\
\hline 22 & 291.7 & Permian 1 & Asselian-Sakmarian \\
\hline 23 & 277.5 & Permian 2 & Artinskian-Kungurian \\
\hline 24 & 265.5 & Permian 3 & Guadalupian \\
\hline 25 & 255.7 & Permian 4 & Lopingian \\
\hline 26 & 248 & Triassic 1 & Induan-Olenekian \\
\hline 27 & 236.5 & Triassic 2 & Anisian-Ladinian \\
\hline 28 & 222.3 & Triassic 3 & Carnian \\
\hline 29 & 208.1 & Triassic 4 & Norian-Rhaetian \\
\hline 30 & 194.6 & Jurassic 1 & Hettangian-Sinemurian \\
\hline 31 & 186.3 & Jurassic 2 & Pliensbachian \\
\hline 32 & 177.3 & Jurassic 3 & Toarcian-Aalenian \\
\hline 33 & 168.2 & Jurassic 4 & Bajocian-Bathonian \\
\hline 34 & 157.8 & Jurassic 5 & Callovian-Kimmeridgian \\
\hline 35 & 148.2 & Jurassic 6 & Tithonian \\
\hline 36 & 141 & Cretaceous 1 & Berriasian-Valanginian \\
\hline 37 & 130.7 & Cretaceous 2 & Hauterivian-Barremian \\
\hline 38 & 118.5 & Cretaceous 3 & Aptian \\
\hline 39 & 105.8 & Cretaceous 4 & Albian \\
\hline 40 & 96.6 & Cretaceous 5 & Cenomanian \\
\hline 41 & 88.5 & Cretaceous 6 & Turonian-Santonian \\
\hline 42 & 77.1 & Cretaceous 7 & Campanian \\
\hline 43 & 68.1 & Cretaceous 8 & Maastrichtian \\
\hline 44 & 60.7 & Cenozoic 1 & Paleocene \\
\hline 45 & 48.1 & Cenozoic 2 & Ypresian-Lutetian \\
\hline 46 & 37.2 & Cenozoic 3 & Bartonian-Priabonian \\
\hline 47 & 28.5 & Cenozoic 4 & Oligocene \\
\hline 48 & 17.3 & Cenozoic 5 & Early-Middle Miocene \\
\hline 49 & 5.8 & Cenozoic 6 & Late Miocene-Pleistocene \\
\hline
\end{tabular}




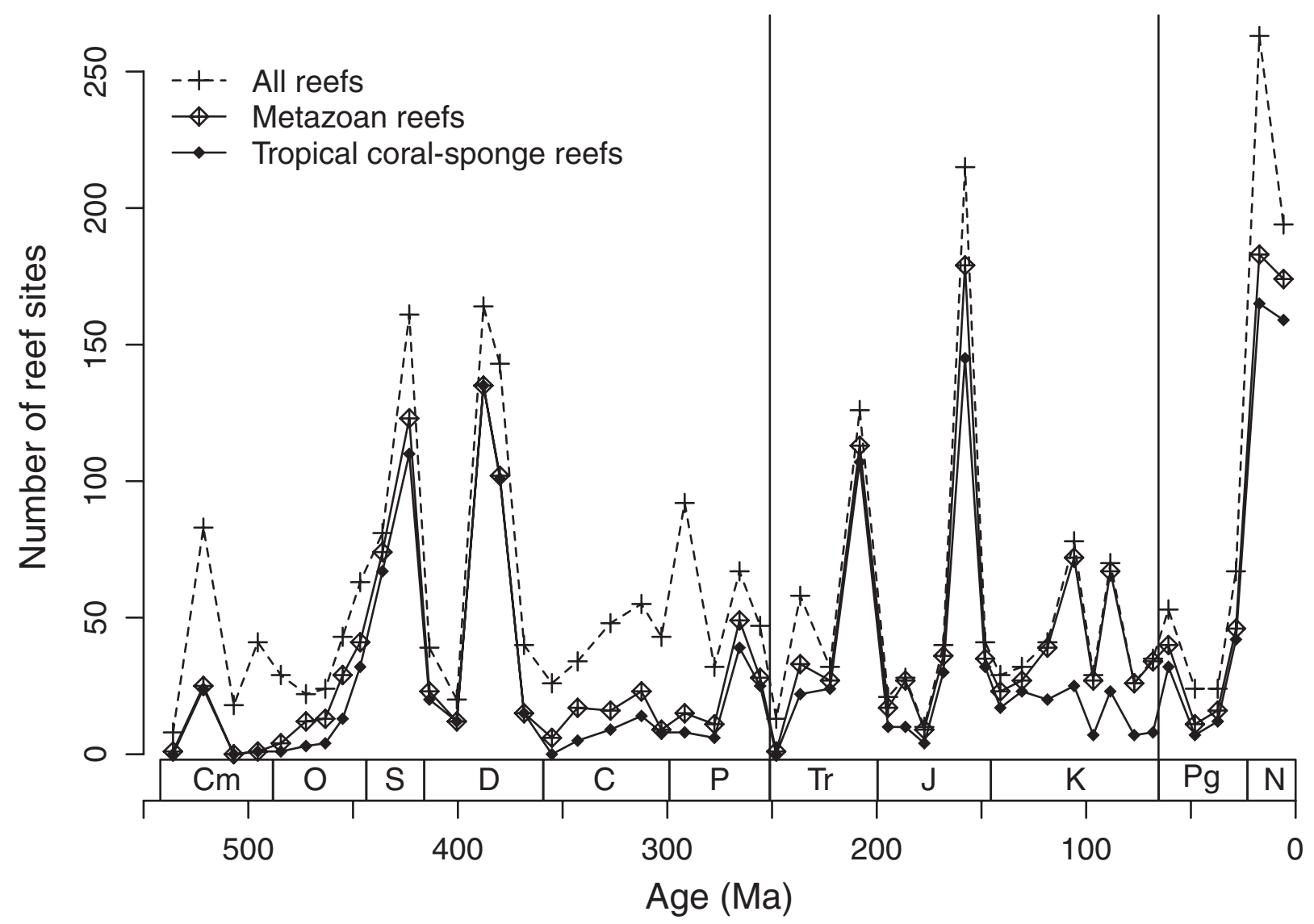

Figure 1. Time series of Phanerozoic reef sites per temporal interval of 49 units of approximately 11 myr duration (see Table 1 ). The dashed line indicates all reefs and buildups recorded in the PaleoReefs database, and the other two lines are subsets of the dataset as described in the legend. Abbreviations of periods are: $\mathbf{C m}$ - Cambrian; $\mathbf{O}$ - Ordovician; $\mathbf{S}-$ Silurian; $\mathbf{D}-$ Devonian; $\mathbf{C}$ - Carboniferous; P - Permian; Tr - Triassic; J - Jurassic; K - Cretaceous; Pg - Paleogene; N - Neogene. The PaleozoicMesozoic and Mesozoic-Cenozoic boundaries are marked by vertical lines.

reefs" curve as well as with each other (Spearman-rank correlation, $\mathrm{r}_{\mathrm{S}}>0.89$ ). The peaks in the three time series usually overlap, which is especially true for the major peaks in the Wenlock-Pridoli (Silurian 2), Middle Devonian and Frasnian (Devonian 3 and 4), NorianRhaetian (Triassic 4), Callovian-Kimmeridgian (Jurassic 5), and Neogene (Cenozoic 5 and 6). The major differences among the curves are in the Cambro-Ordovician and the Carboniferous to Middle Triassic, when metazoan-dominated reefs were depleted relative to microbial and algal reefs. Another departure is between metazoan reefs and coral-sponge reefs for much of the Cretaceous, when rudists were important "reef" builders (see Gili et al. 1995 for discussion). Although the Miocene represents a sampling peak in all time series, only the metazoan and coral-sponge reefs show significant Phanerozoic trends of better sampling in younger intervals $\left(\mathrm{r}_{\mathrm{S}}=0.41, \quad \mathrm{p}=0.004\right.$ and $\mathrm{r}_{\mathrm{S}}=-0.32, \mathrm{p}=0.027$, respectively). The volatility of reef abundance increases with constraints: The "all reefs" time series has the lowest volatility (1.11) and coral-sponge reefs the largest (1.43).

The time series of collection counts shares several attributes with the reef abundance curves (Fig. 2). Although sampling peaks are less pronounced, there are distinct peaks in Silurian 2, Devonian 3, Jurassic 5 and the Neogene (Cenozoic 5 and 6). Autocorrelations are low and not significant for the collection counts. A significant relationship between sampling and age is only evident for the $1 \%$ collections $\left(r_{S}=-0.30, p=0.04\right)$. This is surprising considering the exponential decay of sedimentary rocks (Gregor 1985) and their outcrop area (Raup 1976). For the "all collection" counts this poor match was somewhat expected because, as discussed under "data and methods", the PBDB has deliberately tried to achieve a uniform number of collections from different time bins, rather than just letting the data follow the available material. This is also evident from the low volatility of the curve $(0.63)$. However, the also weak correlation with the $1 \%$ collection counts suggests that paleontological sampling follows the available rock record only weakly. The volatility of the $1 \%$ data (1.40) is similar to the coral-sponge reef data. Although the cross-correlation of first differences between the two sampling curves is significant $\left(r_{S}=0.43, p=0.002\right)$, visual inspection of Fig. 2 shows that sampling peaks do not always match. As already discussed under "data and methods" each of the two curves has its potential biases. Although the 1\% curve may better reflect actual sampling intensity in 


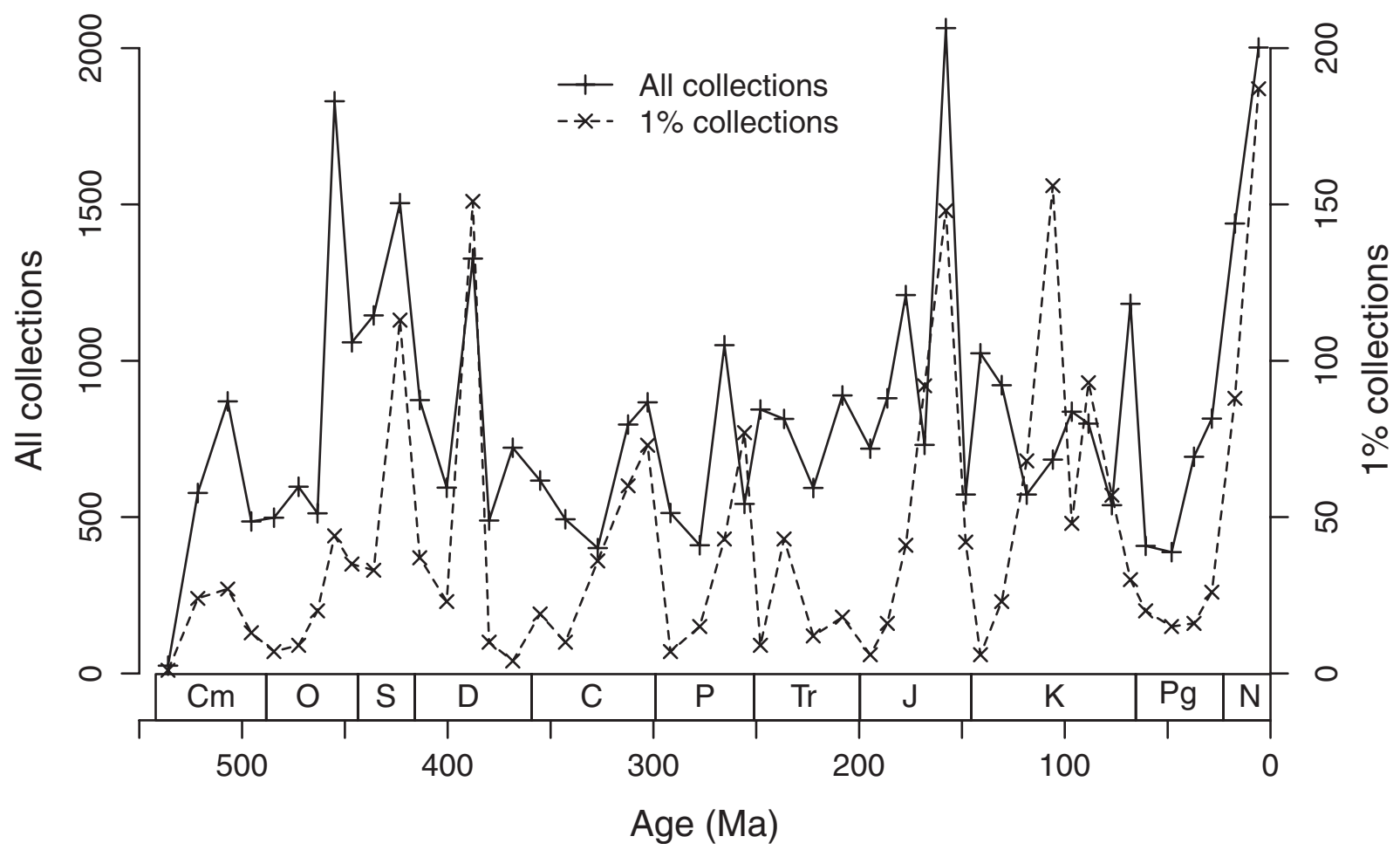

Figure 2. Time series of collection counts in 49 Phanerozoic intervals. "All collections" refers to the total collections in the marine invertebrate working group of the Paleobiology Database. " $1 \%$ collections" indicates the number of collections in the $1 \%$ random selection of the published literature. Note the different scale of the two time series.

the published literature than the total curve, some of the peaks in the former may be deceived by the unusually strong contribution of just a few references. This appears to be true in the Cretaceous (most prominently in the Albian, Cretaceous 4) when sampling peaks in the $1 \%$ curve coincide with sampling lows in the total curve. To identify the potentially most problematic intervals, I have computed the number of collections per reference and interval for the $1 \%$ data. On average 5.9 collections were reported per reference (median $=4.2$ ) and the distribution is strongly right-skewed, which is expected when most references report only a few collections but a few references report many collections. The top three proportions are in Permian 4

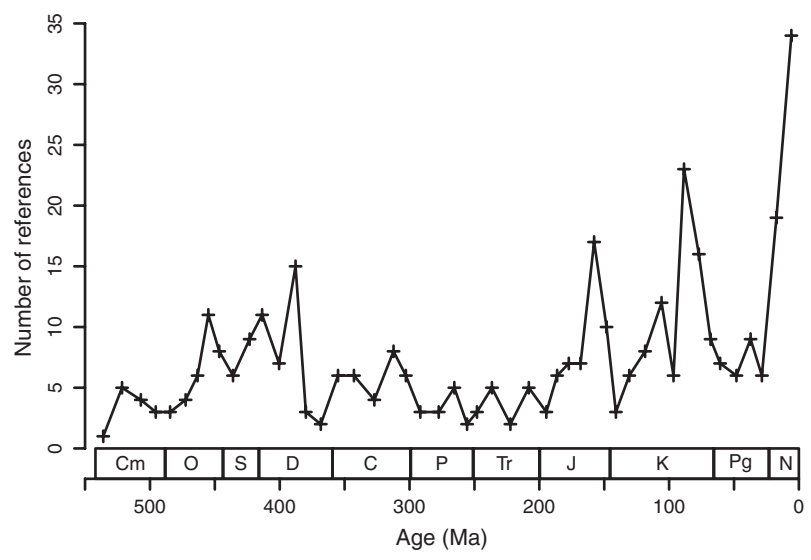

Figure 3. Time series of entered reference counts in the $1 \%$ project.
(38.5 collection per reference), Jurassic 4 (13.1) and Cretaceous 4 (13.0). Counting references instead of collections probably reflects better the actual variations of sampling intensity (Fig. 3), but this approach is biased by low sample size. The reference curve has only a few distinct peaks in Devonian 3, Jurassic 5, Cretaceous 6 and the Neogene and a moderate volatility of 0.73 .

\section{Reef abundance versus sampling}

There are significant cross-correlations between changes in reef abundance and changes in all individual proxies of sampling intensity (Table 2 ). This suggests that changes in reef abundance are partially controlled by changes in sampling intensity. Two general observations from the correlation tests are noteworthy: (1) the correlations are weakest for all reefs and strongest for metazoan reefs; (2) the $1 \%$ collection data give the highest correlation coefficients. The highest correlation was observed between the curves of metazoan reefs and $1 \%$ collections, where $40 \%$ of the variance in reef abundance is explained by changes sampling intensity. Because autocorrelations are usually low, I have also tested the correlations between raw data. These correlations show the same basic results as the first differences. None of the correlations indicate that the pattern of reef abundance is dominantly controlled by the pattern of sampling, which leaves the possibility of processes that are independent of sampling. However, the 
Table 2. Cross-correlations of changes in reef abundance and changes in proxies of sampling intensity.

\begin{tabular}{llll}
\hline & All collections & $1 \%$ collections & $1 \%$ references \\
\hline All reefs & $r_{S}=0.31, p=0.030$ & $r_{S}=0.53, p<0.001$ & $r_{S}=0.42, p=0.003$ \\
Metazoan reefs & $r_{S}=0.41, p=0.004$ & $r_{S}=0.63, p<0.001$ & $r_{S}=0.56, p<0.001$ \\
Coral-sponge reefs & $r_{S}=0.37, p=0.010$ & $r_{S}=0.58, p<0.001$ & $r_{S}=0.48, p<0.001$ \\
\hline
\end{tabular}

correlations need to be taken into account to identify sampling-standardized reef abundance curves.

The logical next step is thus to look at differences between the sampling curves and the reef curves. A qualitative comparison can be done by visual inspection of the raw data (Fig. 4), but a quantitative tests needs to analyze residuals of linear regressions. In addition to analyzing all sampling proxies separately, I have performed multiple regressions of reef abundances versus all possible combinations of sampling proxies to find the combination of variables with the greatest explanatory power. This "best match" was achieved for the combination of " $1 \%$ collections" and "all collections" whose combined changes explain $50 \%$ of the variance in the changes of metazoan reef abundance (the " $1 \%$ references" proxy is uncorrelated in the multiple regression analysis). The following sections discuss standardized residuals of reef abundance regressed against the best individual predictor ( $1 \%$ collections) and that best combination (= best match) of variables.

Although hampered by sometimes autocorrelated time series, the residuals of the raw data are more intuitively understandable are thus reported first. The plots (Fig. 5) are surprisingly uniform in their basic patterns. There is agreement among all plots that most of the Phanerozoic reef record is neither unusually rich nor unusually depleted when viewed against the overall sampling of the fossil record. There is also agreement that there were at least three significant reef peaks relative to sampling intensity: One in the Frasnian (Devo-

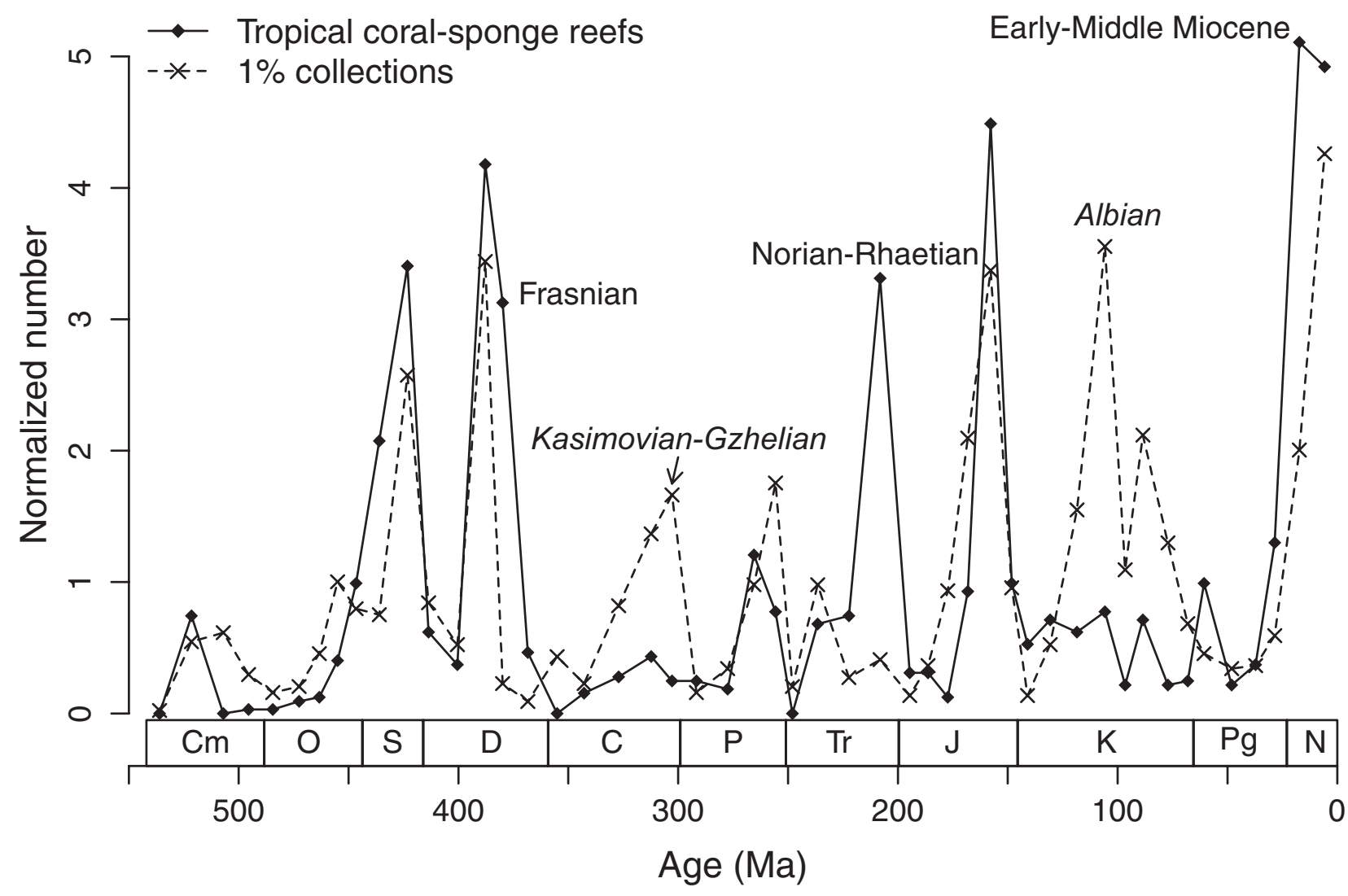

Figure 4. Normalized (individual values divided by mean values) counts of coral-sponge reefs and collections per interval. This example demonstrates how departures between curves can be visually detected. When the solid line is above the dashed line, coral-sponge reefs are relatively more abundant than predicted by the sampling curve and vice versa. Profound positive excursions of reef abundance are visible in the Frasnian, Norian-Rhaetian and Early-Middle Miocene, while negative excursions are visible in the Kasimovian-Gzhelian and Albian. The Late Jurassic sees a peak in both sampling intensity and reef abundance and it is questionable if the Late Jurassic reef boom is significantly larger than predicted by sampling. 

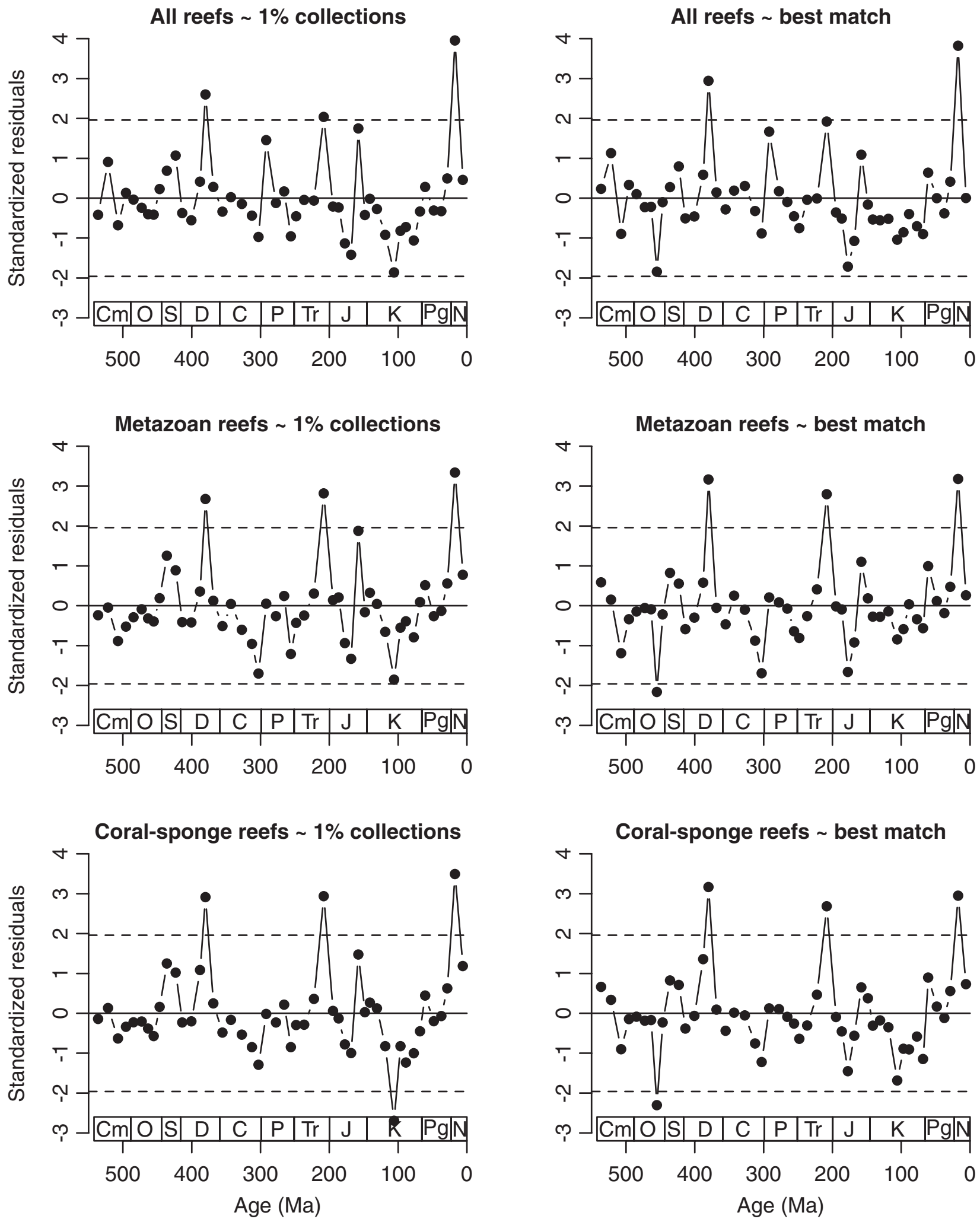

Figure 5. Standardized residuals from the regression of reef counts (Fig. 1) against proxies of sampling intensity of Phanerozoic marine invertebrates (Figs 2,3). The dashed horizontal lines indicate the $95 \%$ individual prediction interval. Values outside this band represent significant outliers in the regression. The plot in the lower left refers to the data plotted in Fig. 4. We can now see that only three positive spikes (Frasnian, Norian-Rhaetian, Early-Middle Miocene) and one negative spike (Albian) represent significant outliers. "Best match" refers to the combination of variables that showed the best fit in a multiple regression analysis (1\% collections + all collections in the PBDB). 
nian 4), one in the Norian-Rhaetian (Triassic 4), and one in the Early to Middle Miocene (Cenozoic 5). It is further interesting that there were very few significant depressions in reef growth relative to sampling and that these depressions were either in the Cretaceous (Albian, Fig. 5 left column) or Ordovician (Caradoc, Fig. 5 right column) rather than in the aftermath of one of the big Phanerozoic mass extinctions, which are notorious for their poor or absent reef record (Flügel \& Kiessling 2002b).

Is the volatility of sampling-standardized reef building lower than in the raw data? To address this question, I have made the raw residual values positive by adding the absolute value of the minimum residual to all values. The volatilities, calculated according to equation (1), are indeed substantially lower for all standardized curves than for the raw curves. Surprisingly the curves, which originally showed the strongest fluctuations, are most affected: the volatility of the coral-sponge reef curve drops from 1.43 in the raw data to 0.47 or 0.56 ( $1 \%$ collections and best match, respectively) in the sampling-standardized curves, a reduction of some $65 \%$. The volatilities in the other curves also drop considerably $(30-40 \%)$. This suggests that the noisiness of the Phanerozoic reef record is partially attributed to heterogeneities in the overall fossil record.

The analysis of first differences allows the detection of unusual changes in reef abundance relative to changes in sampling. This approach takes care of the autocorrelations observed in some time series of reef abundance (see "sampling patterns") and is thus statistically more rigorous. The standardized residuals of the regressions (Fig. 6) indicate a more balanced pattern of significant rises and drops in reef abundance than the previous analysis. Three prominent increases of reef abundance relative to changes in sampling (Triassic 4, Jurassic 5, and Cenozoic 5) are mirrored by three or four substantial declines (Devonian 5, Jurassic 1, Cenozoic 6 , and Jurassic 6 for the $1 \%$ collections). The pronounced negative excursions usually follow strong positive excursions. As in the analyses of raw data, the Big Five mass extinction events (Raup \& Sepkoski 1982) are not pronounced in the sampling-standardized patterns of changes in reef abundance and there generally is a poor match between relative declines in reef abundance and the reported intensity of mass extinctions (Sepkoski 1996; Foote 2003). Just two mass extinctions are matched by significant reef declines: the Frasnian-Famennian crisis and the Triassic-Jurassic mass extinction. Even the Permian-Triassic boundary exhibits only a very minor drop of reef abundance after controlling for sampling. This does not necessarily imply that all the apparent reef crises reported earlier (Flügel \& Kiessling 2002b) are biased by incomplete sampling. Sampling and reef abundance may be affected by the same underlying processes such as sealevel change and plate tectonic regimes (Peters 2005, 2006).

\section{Discussion of a sampling-standardized reef curve}

A closer look at the residuals of the regressions between first differences is worthwhile because these graphs can be easily misread. In addition, the smaller (absolute z-scores of greater than 1) standardized residuals deserve at least some attention because they may hint to meaningful processes. Although all curves depicted in Figs 5 and 6 show some interesting features, I limit the discussion to just one curve: the residuals of changes in tropical coral-sponge reef abundance and changes in collection counts of the $1 \%$ project (lower left-hand graph in Fig. 6, Fig. 7). I use tropical coralsponge reefs because they are the biologically most uniform subset of PARED, which can be traced across the entire Phanerozoic and because the stability of Holocene tropical coral reefs is a major concern in global change biology (Pandolfi et al. 2003; Bellwood et al. 2004; Montaggioni 2005; Pandolfi \& Jackson 2006). I compare changes of coral-sponge reefs with changes in the $1 \%$ collection data because these show the greatest individual cross-correlations among the proxies for sampling intensity. Although the "best match" combination of variables is even better correlated with reef abundance, it is just easier to discuss a single variable and the "all collections" data in the best match are unlikely to truly follow the quality of the fossil record.

Sampling-standardized changes in reef abundance are negligible for most of the Early Paleozoic. The late Early Cambrian reef crisis (Zhuravlev 1996) is seen but does not even reach a z-score of -1 . The Ordovician rise in sampling was just followed by the same proportional rise in reefs and there is no effect of the end-Ordovician mass extinction. The first pronounced reef-decline is seen across the Silurian-Devonian boundary (Fig. 7, number 1). This decline is characterized by both a substantial decline in reef numbers and a reduction in sampling. Although characterized as a minor reef crisis by Flügel and Kiessling (2002), there was concern that relative sea-level changes due to the Caledonian Orogeny (Ronov 1994) introduced a sampling bias (Kiessling 2002). The Middle Devonian and Frasnian rise of reefs (Fig. 7, number 2) is the only example of a substantial reef boom lasting more than one temporal bin. A rise in sampling in the Middle Devonian is paralleled by an even stronger rise of reef abundance and the strong sampling drop in the Frasnian is matched by almost constant reef abundance values. The first significant sampling-standardized decline in the Famennian (Fig. 7, number 3) is due to a strong drop of reef abundance at stable sampling levels. Sea-level changes are thus unlikely to be directly responsible for this reef crisis. A nutrient-triggered crisis due to landplant evolution (Algeo \& Scheckler 1998; Peterhänsel $\&$ Pratt 2001) would well explain why reefs were especially affected while the general extinction intensity was moderate (Foote 2001). The Carboniferous and Per- 

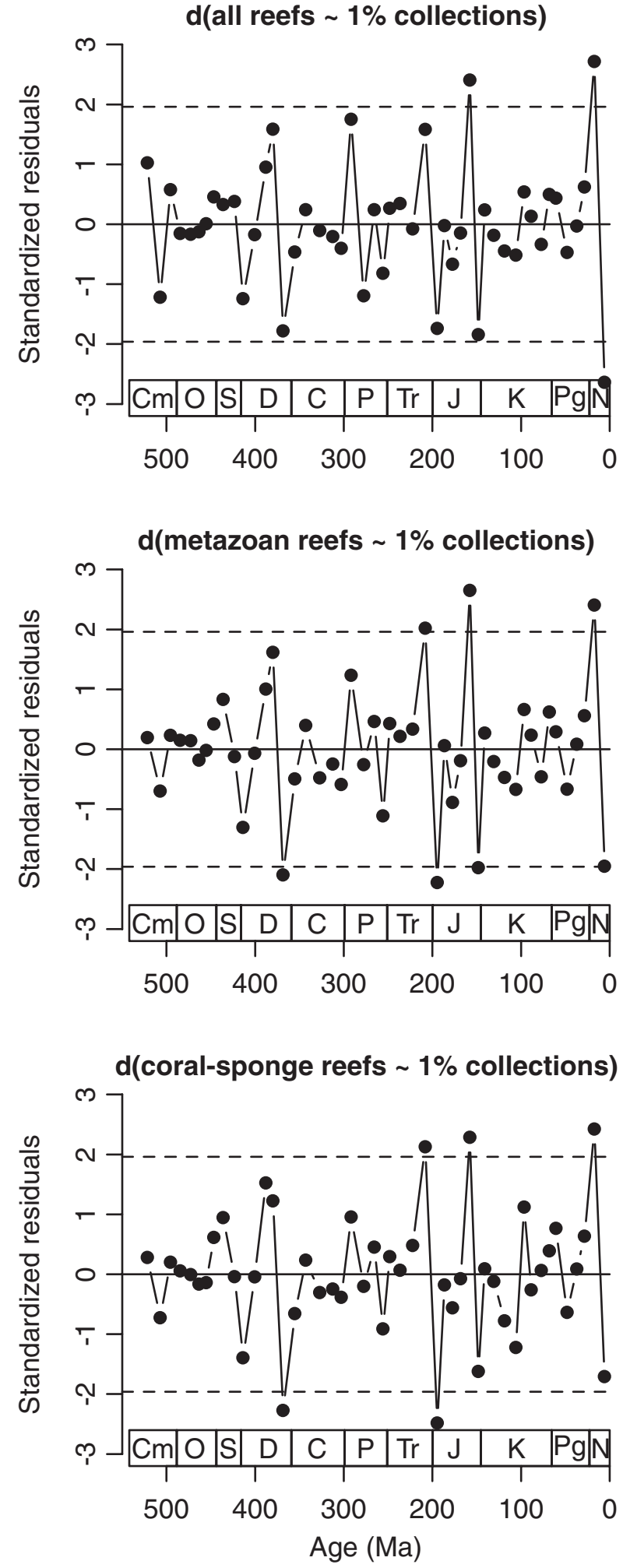
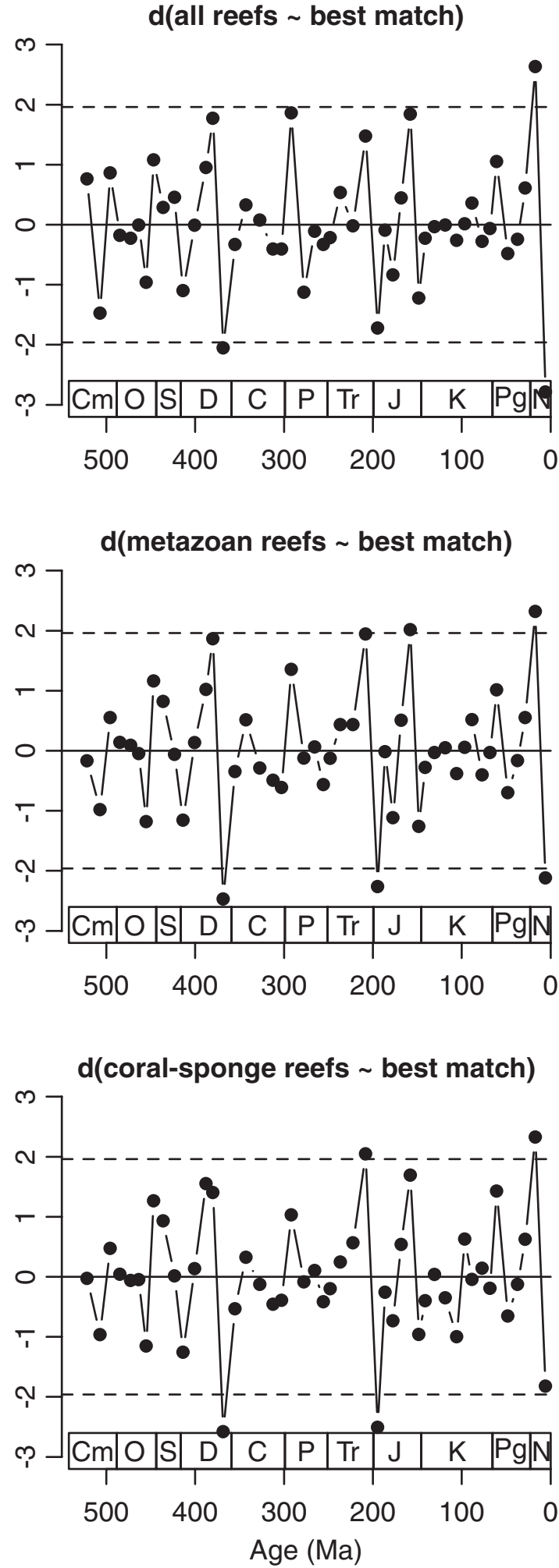

Figure 6. Standardized residuals from the regression of changes in reef counts against changes in proxies of sampling intensity of Phanerozoic marine invertebrates. Note that all values greater than zero indicate sampling-standardized expansions with respect to the previous intervals and all values smaller than zero indicate declines. See Fig. 5 for additional explanations.

mian periods exhibit modest fluctuations and even the end-Permian mass extinction did not result in a reef decline that could not be explained by changes in sampling (Fig. 7, number 4). This is not to say that there was no reef crisis at the Permian-Triassic boundary.
The ecological crisis of reefs is well documented (Weidlich et al. 2003) and until recently no metazoan reefs were reported from the entire Early Triassic (Pruss et al. 2007). In terms of the decline in reef abundance the Early Triassic drop is just too well matched by a 
Coral-sponge reefs $\sim 1 \%$ collections

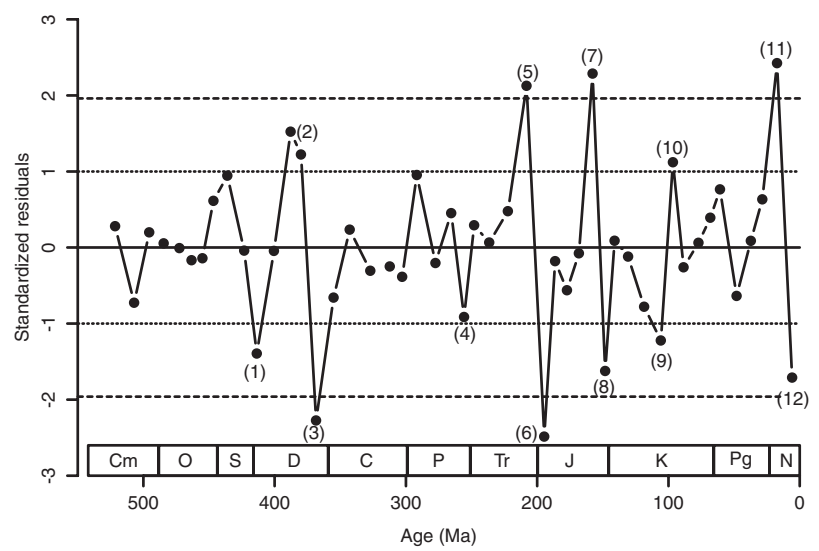

Figure 7. Standardized residuals from the regression of changes in coral-sponge reef counts against changes in $1 \%$ collection counts. Same as lower left-hand graph in Fig. 6, except that z-values of plus and minus 1 are marked by stippled lines and changes discussed in the text are numbered.

similar drop in sampling to suspect biologically meaningful patterns from the abundance data alone.

The first significant rise in sampling-standardized reef abundance is evident in the Norian-Rhaetian interval and was followed by an also significant drop in the Hettangian-Sinemurian (Fig. 7, numbers 5-6). This pattern suggests that both the Norian-Rhaetian reef expansion and the Early Jurassic collapse have causes that would not affect sampling levels. Changes in nutrient regimes are held responsible for the former (Flügel 2002) and abrupt temperature rises for the latter (Marzoli et al. 2004; Kiessling \& Aberhan 2007). The significant Callovian-Kimmeridgian rise of reef abundance (Fig. 7 number 7) comes as a surprise, because both coral-sponge reefs and sampling increase substantially in this interval (Figs 1, 2). The expansion of reefs, however, is proportionally much larger than the increase in sampling, so that the standardized residual is the second largest in the entire Phanerozoic. A suite of climatic, oceanographic and biological changes is currently discussed to explain the dramatic Late Jurassic (especially late Oxfordian-Kimmeridgian) reef boom (Leinfelder et al. 2002; Cecca et al. 2005). An explanation for the subsequent Tithonian decline (Fig. 7, number 8) cannot be offered. Flügel and Kiessling (2002) noted a third order reef decline but found the most dramatic collapse across the Jurassic-Cretaceous boundary, when the sampling standardized data show no deviation at all. The decline of coral reefs in the late Early Cretaceous and the Cenomanian spike (Fig. 7, numbers 910) should be interpreted with care, because here the results vary most strongly among proxies of sampling intensity. The agreement in the Cenozoic, however, suggests that the Early Neogene reef expansion (Fig. 7, number 11) is significant and a biological reality. This proliferation in spite of long-term global cooling (superimposing the mid-Miocene climatic optimum) can perhaps be explained by a relative increase in low- nutrient habitat area, due to a reduction of equatorial upwelling (Perrin \& Kiessling in press). The dramatic drop in the Late Miocene to Pleistocene was not expected from the raw data, which suggest stability (Fig. 1). A late Miocene-Pliocene reef reduction has been previously suggested (Veron 1995) but attributed to a loss of habitat area owing to glacio-eustatic regressions, which should affect all marine life. Further climatic cooling could be responsible but I should emphasize a potential bias in PARED here. The reef data for the Late Miocene and Pliocene are fairly complete, but Pleistocene reefs were only recently entered into PARED and sampling is still incomplete. There are, however, many Pleistocene records in the $1 \%$ collection data (51 of 187 in Cenozoic 6), which artificially raises sampling estimates relative to reef counts.

\section{Implications}

We have seen that a substantial part of the changes in reef abundance can be explained by changes in paleontological sampling. None of our available proxies for sampling is perfect, but the concordance of the results among the three proxies studied herein suggests that the data are sufficiently robust to reach solid conclusions.

Sampling itself is controlled by a variety of factors, among them geologic (weathering, burial, diagenesis, metamorphosis, subduction), geomorphologic and climatic (accessible outcrop area), socioeconomic, physical (ancient sea level, tectonics) and biological (changes in skeletal mineralogy, productivity). Only the latter two factors have some biological bearing: Sea level and hypsography control habitat area that is known to have a significant influence on both diversity and abundance of organisms in general and reefs in particular (Bellwood \& Hughes 2001; Kiessling 2005a). Sealevel changes and tectonic factors that lead to the formation and destruction of marine habitats are currently discussed as the "common cause" scenario, which would affect sampling regimes, biodiversity and ecosystems simultaneously (Peters 2005, 2006). Evolutionary or ecological changes influencing the durability of shells or productivity are also of major interest in paleobiology (Martin 1995, 1996; Kershaw \& Brunton 1999; Kidwell 2005). These factors are sacrificed when departures between sampling and the fossil record of an ecosystem are analyzed. The parallel waxing and waning of paleontological sampling and preserved reef abundance may be real and causally related, thus not strictly representing a bias. However, with the standardization for sampling one can approach factors that are otherwise hidden.

What conclusions can be drawn from the residuals and are they in agreement with our current understanding of reef development? I think the most interesting aspect of my results is the observation of substantial reef declines often following substantial expansions 
(Late Devonian, Triassic-Jurassic boundary, Late Jurassic, Neogene), which occur under very different environmental conditions. Although all individual reef booms and bursts can perhaps also be explained by specific environmental and biological changes (see previous section), the big picture suggests more general principles that might be driven by intrinsic dynamics rather than environmental change. This phenomenon, known as selforganized criticality, is a property of many dynamical systems that have a critical point as an attractor and are scale-invariant (Bak et al. 1987; Solé et al. 2002). In ecology, self-criticality is often inferred for complex ecosystems (Solé et al. 2002) and has also been suggested for carbonate sedimentation (Drummond \& Dugan 1999). It would thus seem reasonable that complex carbonate ecosystems such as reefs should exhibit properties of self-organized criticality. If self-organization is actually present in Phanerozoic reef building (further tests are clearly required), then the paradigm of reefs as passive tracers of global change should be revisited.

\section{Conclusions}

The waxing and waning of Phanerozoic reefs is mostly in concord with the increase and decrease of paleontological sampling. Controlling for sampling greatly reduces the volatility in reef abundance and leaves only a few prominent intervals of reef expansion and subsequent decline. The standardization may overcompensate for bias because reef abundance and sampling can be causally related through large-scale variations of sea-level, oceanography or plate tectonic regimes. However, sampling standardization opens new opportunities for detecting signals in reef building that are not sampling-driven. The substantial fluctuations in sampling-standardized reef abundance thus demand specific attention. The typical pattern of substantial changes in reef abundance appears to be rapid expansions followed by collapse. If collapse is a consequence of expansion, then the focus of future research should be on the causes of extensive reef expansions such as those seen in the Middle Devonian-Frasnian, Late Triassic, Late Jurassic and early Neogene.

\section{Acknowledgements}

The idea for this paper stems from a research visit to the Santa $\mathrm{Fe}$ Institute. I am grateful to Doug Erwin for inviting me there and to the Santa Fe Institute for logistic and financial support. Michael Foote and Lucien Montaggioni provided constructive and insightful reviews. I thank Uta Merkel for diligently entering data into the Paleobiology Database. Martin Aberhan and Loic Villier contributed substantially to the $1 \%$ project. The study was supported by the VolkswagenStiftung. This is Paleobiology Database publication \#66.

\section{References}

Algeo, T. J. \& Scheckler, S. E. 1998. Terrestrial-marine teleconnections in the Devonian - Links between the evolution of land plants, weathering processes, and marine anoxic events. - Philo- sophical Transactions of the Royal Society of London Series B Biological Sciences 353: 113-128.

Bak, P., Tang, C. \& Wiesenfeld, K. 1987. Self-organized criticality: An explanation of the $1 / \mathrm{f}$ noise. - Physical Review Letters 59: 381-384.

Bellwood, D. R. \& Hughes, T. P. 2001. Regional-scale assembly rules and biodiversity of coral reefs. - Science 292: 1532-1535.

Bellwood, D. R., Hughes, T. P., Folke, C. \& Nyström, M. 2004. Confronting the coral reef crisis. - Nature 429: 827-833.

Cecca, F., Martin Garin, B., Marchand, D., Lathuiliere, B. \& Bartolini, A. 2005. Paleoclimatic control of biogeographic and sedimentary events in Tethyan and peri-Tethyan areas during the Oxfordian (Late Jurassic). - Palaeogeography, Palaeoclimatology, Palaeoecology 222: 10-32.

Copper, P. 1988. Ecological succession in Phanerozoic reef ecosystems: is it real? - Palaios 3: 136-152.

Cowen, R. 1988. The role of algal symbiosis in reefs through time. Palaios 3: 221-227.

Drummond, C. N. \& Dugan, P. J. 1999. Self-organizing models of shallow-water carbonate accumulation. - Journal of Sedimentary Research 69: 939-946.

Flügel, E. 2002. Triassic reef patterns. In Kiessling, W., Flügel, E. \& Golonka, J. (eds). Phanerozoic Reef Patterns: 391-463, SEPM Special Publication 72, Tulsa.

Flügel, E. \& Kiessling, W. 2002a. A new look at ancient reefs. In Kiessling, W., Flügel, E. \& Golonka, J. (eds). Phanerozoic Reef Patterns. SEPM Special Publication 72, Tulsa: pp. 3-10.

Flügel, E. \& Kiessling, W. 2002b. Patterns of Phanerozoic reef crises. In Kiessling, W., Flügel, E. \& Golonka, J. (eds). SEPM Special Publication 72, Tulsa: pp. 691-733

Foote, M. 2001. Inferring temporal patterns of preservation, origination, and extinction from taxonomic survivorship analysis. - Paleobiology 27: 602-630.

Foote, M. 2003. Origination and extinction through the Phanerozoic: a new approach. - Journal of Geology 111: 125-148.

Gili, E., Masse, J. P. \& Skelton, P. W. 1995. Rudists as gregarious sediment dwellers, not reef builders, on Cretaceous carbonate platforms. - Palaeogeography, Palaeoclimatology, Palaeoecology 118: $245-267$.

Gregor, C. B. 1985. The mass-age distribution of Phanerozoic sediments. In Snelling, N. J. (ed.). The Chronology of the Geologic Record. Geological Society of America, Memoir 10, Boulder: pp. 284-289.

Hallock, P. 1997. Reefs and reef limestones in earth history. In Birkeland, C. (ed.). Life and Death of Coral Reefs. Chapman \& Hall, New York: pp. 13-42.

James, N.P. 1983. Reef environment. In Scholle, P. A., Bebout, D. G. \& Moore, C. H. (eds). Carbonate Depositional environments AAPG Memoir 33, Tulsa: pp. 345-440.

James, N. P. \& Bourque, P.-A. 1992. Reefs and mounds. In Walker, R. G. \& James, N. P. (eds). Facies Models: Response to Sea Level Change. Geological Association of Canada, St. John's: pp. 323-347.

Kershaw, S. \& Brunton, F. R. 1999. Palaeozoic stromatoporoid taphonomy: ecologic and environmental significance. - Palaeogeography, Palaeoclimatology, Palaeoecology 149: 313-328.

Kidwell, S. M. 2005. Shell composition has no net impact on largescale evolutionary patterns in mollusks. - Science 307: 914-917.

Kiessling, W. 2002. Secular variations in the Phanerozoic reef ecosystem. In Kiessling, W., Flügel, E. \& Golonka, J. (eds). Phanerozoic Reef Patterns. SEPM Special Publication 72, Tulsa: pp. 625-690.

Kiessling, W. 2005a. Habitat effects and sampling bias on Phanerozoic reef distribution. - Facies 51: 27-35.

Kiessling, W. 2005b. Long-term relationships between ecological stability and biodiversity in Phanerozoic reefs. - Nature 433: 410413.

Kiessling, W. 2006. Towards an unbiased estimate of fluctuations in reef abundance and volume during the Phanerozoic. - Biogeosciences 3: 15-27.

Kiessling, W. \& Aberhan, M. 2007. Environmental determinants of marine benthic biodiversity dynamics through Triassic-Jurassic times. - Paleobiology 33: 414-434. 
Kiessling, W. \& Flügel, E. 2002. Paleoreefs - a database on Phanerozoic reefs. In Kiessling, W., Flügel, E. \& Golonka, J. (eds). Phanerozoic Reef Patterns. SEPM Special Publication 72, Tulsa: pp. 77-92.

Kiessling, W., Flügel, E. \& Golonka, J. 1999. Paleoreef maps: Evaluation of a comprehensive database on Phanerozoic reefs. - AAPG Bulletin 83: 1552-1587.

Kiessling, W., Flügel, E. \& Golonka, J. 2000. Fluctuations in the carbonate production of Phanerozoic reefs. In Insalaco, E., Skelton, P. W. \& Palmer, T. J. (eds). Carbonate Platform Systems: components and interactions. Geological Society Special Publication 178, London: pp. 191-215.

Leinfelder, R. R., Schmid, D. U., Nose, M. \& Werner, W. 2002. Jurassic reef patterns - the expression of a changing globe. In Kiessling, W., Flügel, E. \& Golonka, J. (eds). Phanerozoic Reef Patterns. SEPM Special Publication 72, Tulsa: pp. 465-520.

Martin, R. E. 1995. Cyclic and secular variation in microfossil biomineralization: clues to the biogeochemical evolution of Phanerozoic oceans. - Global and Planetary Change 11: 1-23.

Martin, R. E. 1996. Secular increase in nutrient levels through the Phanerozoic: implications for productivity, biomass, and diversity of the marine biosphere. - Palaios 11: 209-219.

Marzoli, A., Bertrand, H., Knight, K. B., Cirilli, S., Buratti, N., Vérati, C., Nomade, S., Renne, P. R., Youbi, N., Martini, R., Allenbach, K., Neuwerth, R., Rapaille, C., Zaninetti, L. \& Bellieni, G. 2004. Synchrony of the Central Atlantic magmatic province and the Triassic-Jurassic boundary climatic and biotic crisis. - Geology 32: 973-976.

Montaggioni, L. F. 2005. History of Indo-Pacific coral reef systems since the last glaciation: Development patterns and controlling factors. - Earth-Science Reviews 71: 1-75.

Pandolfi, J. M., Bradbury, R. H., Sala, E., Hughes, T. P., Bjorndal, K. A., Cooke, R. G., McArdle, D., McClenachan, L., Newman, M. J. H., Paredes, G., Warner, R. R. \& Jackson, J. B. C. 2003. Global trajectories of the long-term decline of coral reef ecosystems. Science 301: 955-958.

Pandolfi, J. M. \& Jackson, J. B. C. 2006. Ecological persistence interrupted in Caribbean coral reefs. - Ecology Letters 9: 818-826.

Perrin, C. \& Kiessling, W. in press. Latitudinal trends in Cenozoic reef patterns and their relationship to climate. - IAS Special Publications.
Peterhänsel, A. \& Pratt, B. R. 2001. Nutrient-triggered bioerosion on a giant carbonate platform masking the postextinction Famennian benthic community. - Geology 29: 1079-1082.

Peters, S. E. 2005. Geologic constraints on the macroevolutionary history of marine animals. - Proceedings of the National Academy of Science USA 102: 12326-12331.

Peters, S. E. 2006. Genus extinction, origination, and the durations of sedimentary hiatuses. - Paleobiology 32: 387-407.

Pruss, S. B., Payne, J. L. \& Bottjer, D. J. 2007. Placunopsis bioherms: the first metazoan buildups following the end-Permian mass extinction. - Palaios 22: 17-23.

Raup, D. M. 1976. Species diversity in the Phanerozoic: an interpretation. - Paleobiology 2: 289-297.

Raup, D. M. \& Sepkoski, J. J., Jr. 1982. Mass extinctions in the marine fossil record. - Science 215: 1501-1503.

Ronov, A. B. 1994. Phanerozoic transgressions and regressions on the continents: a quantitative approach based on areas flooded by the sea and areas of marine and continental deposition. - American Journal of Science 294: 777-801.

Sepkoski, J. J., Jr. 1996. Patterns of Phanerozoic extinction: a perspective from global data bases. In Walliser, O. H. (ed.). Global Events and Event Stratigraphy in the Phanerozoic. Springer, Berlin: pp. $35-51$.

Solé, R. V., Alonso, D. \& McKane, A. 2002. Self-organized instability in complex ecosystems. - Philosophical Transactions of the Royal Society of London Series B-Biological Sciences 357: 667-681.

Veron, J. E. M. 1995. Corals in space and time. Cornell Press, Ithaca. Webb, G. E. 1996. Was Phanerozoic reef history controlled by the distribution of non-enzymatically secreted reef carbonates (microbial carbonate and biologically induced cement)? - Sedimentology 43: 947-971.

Weidlich, O., Kiessling, W. \& Flügel, E. 2003. The Permian-Triassic boundary interval as a model for forcing marine ecosystem collapse by long-term atmospheric oxygen drop. - Geology 31: 961-964.

Wood, R. 1993. Nutrients, predation and the history of reef-building. - Palaios 8: 526-543.

Zhuravlev, A. Y. 1996. Reef ecosystem recovery after the Early Cambrian extinction. In Hart, M. B. (ed). Biotic recovery from mass extinction events. Geological Society of London Special Publication 102, London: pp. 79-96. 